\title{
VALIDIFICATION OF SMART-COP IN PREDICTING THE NEED FOR IRVS IN COMMUNITY ACQUIRED PNEUMONIA (CAP) PATIENTS
}

\author{
Uphar Gupta1, Prabhakar K², Vidyasagar C. $R^{3}$, Lakshmaiah $V^{4}$, Raghvendra Prasad B. $N^{5}$, Raveesha $A^{6}$ \\ 1 Post Graduate Student, Department of General Medicine, Sri Devaraj Urs Medical College, Kolar. \\ ${ }^{2}$ Professor and HOD, Department of General Medicine, Sri Devaraj Urs Medical College, Kolar. \\ 3 Professor, Department of General Medicine, Sri Devaraj Urs Medical College, Kolar. \\ ${ }^{4}$ Professor, Department of General Medicine, Sri Devaraj Urs Medical College, Kolar. \\ 5 Professor, Department of General Medicine, Sri Devaraj Urs Medical College, Kolar. \\ 6Professor, Department of General Medicine, Sri Devaraj Urs Medical College, Kolar.
}

\section{ABSTRACT}

Pneumonia has been considered a health problem for ages. Despite being the cause of significant morbidity and mortality. Delay in ICU admission of CAP patients has been shown to be associated with increased mortality. The 'SMART-COP' is a simple tool that is the result of an extensive study on CAP called the Australian CAP Study (ACAPS).

\section{OBJECTIVE}

To assess the validity the SMART-COP severity scoring tool in patients of Community Acquired Pneumonia (CAP).

\section{MATERIALS AND METHODS}

Fifty patients of CAP admitted in the intensive care units of R. L. Jalappa Hospital, Kolar, above the age of 18yrs with a diagnosis of community acquired pneumonia.

\section{RESULTS}

We noted a progression in the need for ICU support and need for ventilatory and ionotropic support with increasing score assigned on the SMART-COP. Thirty day mortality in the patients also showed a linear pattern with increase in the score assigned to the patients. Mortality was high in the very high risk group and high risk group.

\section{CONCLUSION}

With $68.5 \%$ of the patients requiring invasive ventilator support and $75 \%$ of the patients requiring inotropic support in the high risk group, it can be safely concluded that SMART-COP scoring system can be used in the patients of community acquired pneumonia to predict the need for IRVS.

\section{KEYWORDS}

Community Acquired Pneumonia, SMART-COP.

HOW TO CITE THIS ARTICLE: Uphar Gupta, Prabhakar K, Vidyasagar C. R, Lakshmaiah V, Raghvendra Prasad B. N, Raveesha A. "Validification of Smart-Cop in Predicting the need for IRVS in Community Acquired Pneumonia (CAP) Patients." Journal of Evolution of Medical and Dental Sciences 2015; Vol. 4, Issue 101, December 17; Page: 16602-16604,

DOI: $10.14260 /$ jemds/2015/2476

\section{INTRODUCTION}

In 1901 William Osler described pneumonia as the "captain of the men of death." He described the condition as "the friend of the aged," allowing them a merciful release from "those cold gradations of decay that make the last state of all so distressing". ${ }^{1}$

Community-Acquired Pneumonia (CAP) is a major cause of morbidity and mortality worldwide pneumonia has been considered a health problem for ages. Despite being the cause of significant morbidity and mortality. Delay in ICU admission of CAP patients has been shown to be associated with increased mortality.

The pneumonia is typically classified as Communityacquired and Hospital-acquired or Healthcare-associated.

Financial or Other, Competing Interest: None.

Submission 17-11-2015, Peer Review 18-11-2015,

Acceptance 10-12-2015, Published 15-12-2015.

Corresponding Author:

Dr. Uphar Gupta

PG Men's Hostel,

SDUMC, Kolar.

E-mail:druphar@gmail.com

DOI:10.14260/jemds/2015/2476
Community Acquired Pneumonia (CAP) is a common disorder with an incidence of about $20 \%$ to $30 \%$ in developing countries compared to an incidence of $3 \%$ to $4 \%$ in developed countries. ${ }^{1,2}$ The mortality of patients with severe Community Acquired Pneumonia (CAP) requiring admission to an Intensive Care Unit (ICU) is high. This is likely to be particularly evident in a developing country like ours, where availability of ICU beds is limited and only critically ill patients in need of assisted ventilation are admitted.3,4

The 'SMART-COP' (systolic blood pressure, multilobar chest radiography involvement, albumin level, respiratory rate, tachycardia, confusion, oxygenation, and arterial $\mathrm{pH}$ ) is a simple tool that is the result of an extensive study on CAP called the Australian CAP Study (ACAPS). ${ }^{5}$ The tool was designed to overcome the limited ability of PSI and CURB 65 to predict, which patients will require Intensive Respiratory or Vasopressor Support (IRVS). SMART-COP is a simple, practical clinical tool for accurately predicting the need for IRVS and helps determine CAP severity. ${ }^{6}$

\section{OBJECTIVE}

To assess the validity, the SMART-COP severity scoring tool in patients of Community Acquired Pneumonia (CAP). 


\section{MATERIALS AND METHODS}

Fifty patients of CAP admitted in the intensive care units of R.L. Jalappa Hospital, Kolar, above the age of 18yrs with a diagnosis of community acquired pneumonia.

\section{Patients were diagnosed as suffering from CAP if they} have

i. Fever or hypothermia, tachypnoea, cough with or without sputum, dyspnoea, chest discomfort, sweats or rigors (or both).

ii. Bronchial breath sounds or inspiratory crackles on chest auscultation.

iii. Parenchymal opacity on chest radiograph. iv. Symptoms occur outside of the hospital or within 48 hours of hospital admission in a patient not residing in a long-term care facility.

An informed consent was taken.

Detailed history was taken and examination was carried out, noted and entered in a structured proforma.

\section{The following investigations were done}

1. Chest X-ray.

2. Serum Albumin.

3. Arterial blood gas analysis.

The patient were monitored for the need for intensive respiratory and vasopressor support.

The data hence obtained was used using the following protocol:

\begin{tabular}{|c|c|c|c|}
\hline & \multicolumn{2}{|c|}{ CAP confirmed on chest X-ray } & \\
\hline \multicolumn{2}{|c|}{50 years old or less } & \multicolumn{2}{|c|}{ more than 50 years old } \\
\hline S systolic BP less than $90 \mathrm{mmHg}$ & 2 points & S systolic BP less than $90 \mathrm{mmHg}$ & 2 points \\
\hline M multilobar CXR involvement & 1 point & M multilobar CXR involvement & 1 point \\
\hline A albumin less than $35 \mathrm{~g} / \mathrm{L}$ & 1 point & A albumin less than $35 \mathrm{~g} / \mathrm{L}$ & 1 point \\
\hline $\begin{array}{l}\mathrm{R} \text { respiratory rate } 25 \text { breaths/min } \\
\text { or more }\end{array}$ & 1 point & $\begin{array}{l}\mathbf{R} \text { respiratory rate } 30 \text { breaths/min } \\
\text { or more }\end{array}$ & 1 point \\
\hline $\mathbf{T}$ tachycardia $125 \mathrm{bpm}$ or more & 1 point & $\mathrm{T}$ tachycardia $125 \mathrm{bpm}$ or more & 1 point \\
\hline C confusion (acute) & 1 point & C confusion (acute) & 1 point \\
\hline $\begin{array}{l}\text { O oxygen low } \\
\mathrm{PaO}_{2} \text { less than } 70 \mathrm{mmHg} \text {, or } \\
\mathrm{O}_{2} \text { saturation } 93 \% \text { or less, or } \\
\mathrm{PaO}_{2} / \mathrm{FiO}_{2} \text { less than } 333\end{array}$ & 2 points & $\begin{array}{l}\text { O oxygen low } \\
\mathrm{PaO}_{2} \text { less than } 60 \mathrm{mmHg} \text {, or } \\
\mathrm{O}_{2} \text { saturation } 90 \% \text { or less, or } \\
\mathrm{PaO}_{2} / \mathrm{FiO}_{2} \text { less than } 250\end{array}$ & 2 points \\
\hline \multirow[t]{2}{*}{ P pH less than 7.35} & 2 points & P pH less than 7.35 & 2 points \\
\hline & \multicolumn{2}{|c|}{ Total points score (maximum 11) } & \\
\hline
\end{tabular}

The interpretation of SMART-COP score was done as follows:

- $0-2$ points: Low risk of needing Intensive Respiratory or Vasopressor Support (IRVS).

- 3-4 points: Moderate risk (1 in 8) of needing IRVS.

- 5-6 points: High risk (1 in 3) of needing IRVS.

- 7 or more points: Very high risk (2 in 3) of needing IRVS.

This was matched with the need for need of intensive respiratory and vasopressor support and thus SMART-COP as a tool was validated with the help of statistical analysis.

This was a prospective study.

\section{RESULTS}

The study included 50 patients diagnosed as cases of community acquired pneumonia; $26(52 \%)$ patients were females compared to $24(48 \%)$ male patients. Of the patients examined and investigated, 17 patients were given invasive ventilatory support and 20 patients were given inotropic support in form of dopamine or noradrenaline or both. These patients were tabulated in bar chart against the SMART-COP score calculated for them.

In the low risk category (Score 0-2 points) none of the patients required inotropic support or invasive ventilatory support. Out of the 7 patients in moderate risk category (Score 3-4 points), 2(28.5\%) patients' required inotropic support or invasive ventilatory support or both. Out of the 9 patients in high risk category (Score 5-6 points), 4(44.5\%) patients required inotropic support and $6(66.67 \%)$ patients required invasive ventilatory support or both. In the very high risk category (score 7 and above points) 16 cases were admitted, $11(68.5 \%)$ patients required inotropic support and 12(75\%) patients required invasive ventilatory support or both.

Comparing thus the need for IRVS was much higher in the patients in very high and high risk categories than in the moderate and low risk categories. 


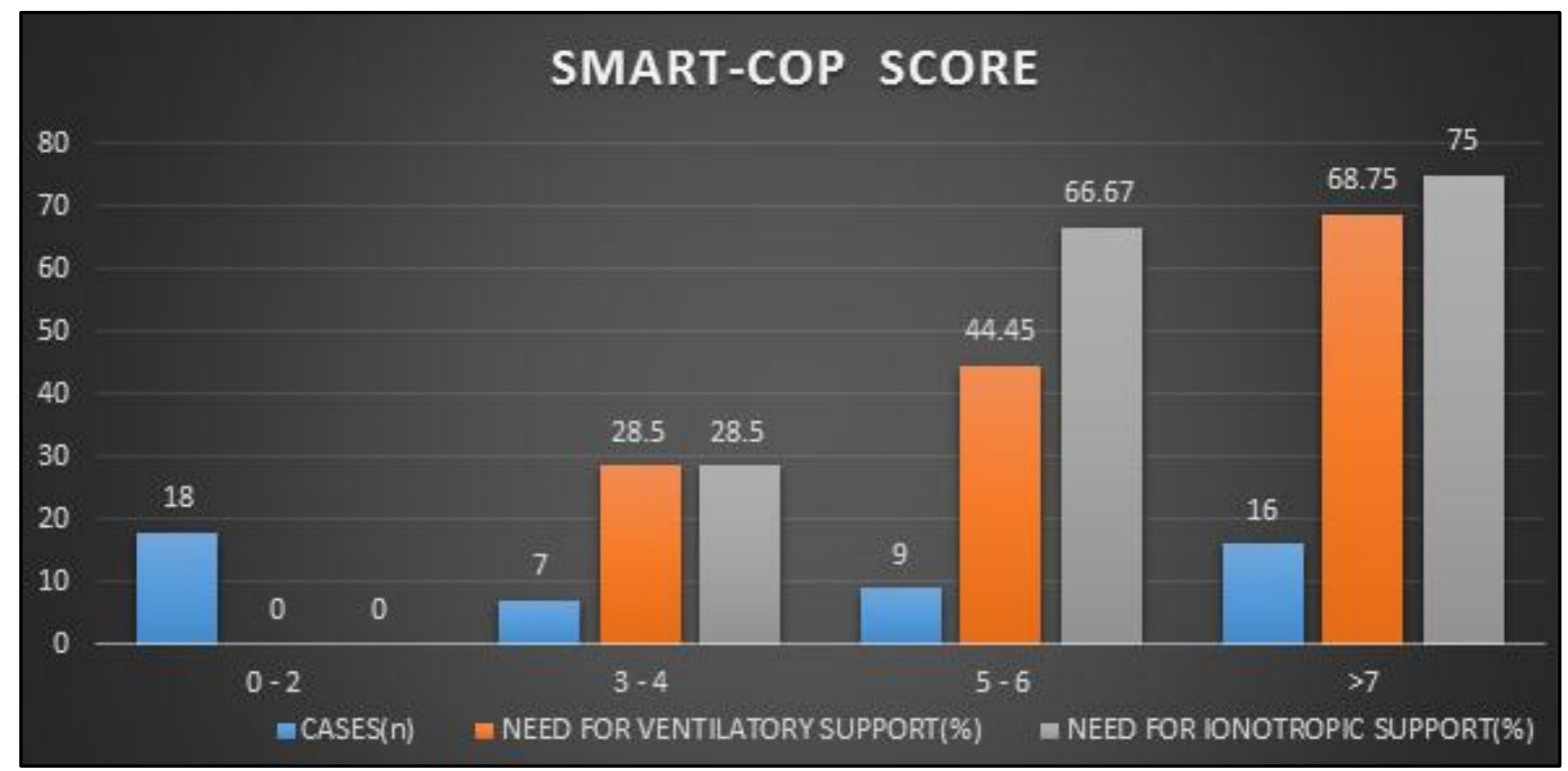

Thirty day mortality in the patients also showed a linear pattern with increase in the score assigned to the patients. Mortality was high $(37.5 \%)$ in the very high risk group and $11.12 \%$ in high risk group. In our study, no mortality was noted in the moderate risk and low risk groups.

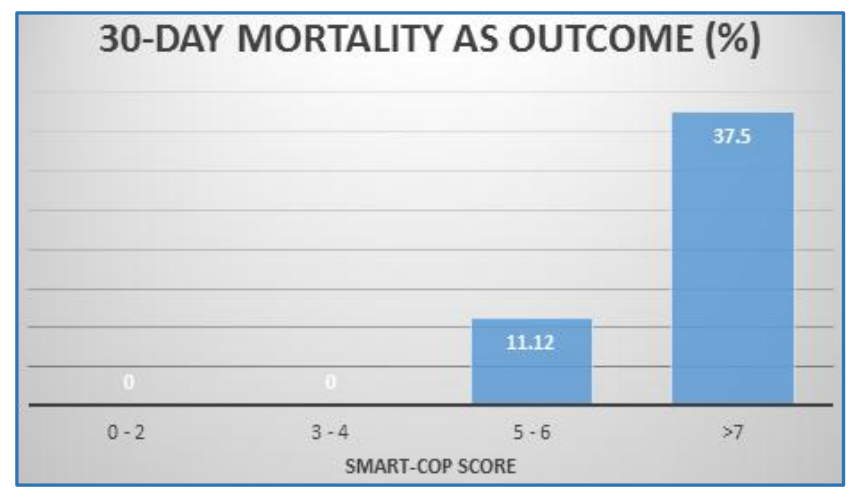

\section{DISCUSSION}

SMART-COP is a simple, practical clinical tool for accurately predicting the need for IRVS that is likely to assist clinicians in determining CAP severity. Current pneumonia severity assessment tools, such as PSI and CURB-65 aim to predict the likely 30-day mortality, but this outcome is heavily dependent on the patient's age and comorbid illnesses, so these tools may not necessarily predict the need for ICU admission or IRVS.7,8

Increasing SMART-COP scores were associated with an increasing likelihood of requiring IRVS. ${ }^{9}$

\section{CONCLUSION}

With $68.5 \%$ of the patients requiring invasive ventilator support and $75 \%$ of the patients requiring inotropic support in the high risk group, it can be safely concluded that SMARTCOP scoring system can be used in the patients of community acquired pneumonia to predict the need for IRVS.

\section{LIMITATIONS}

A sample size of 50 patients with community acquired pneumonia admitted to intensive care units was taken for this study. A larger sample size would have improved the confidence in the findings and a clearer pattern could have been demonstrated.

The need for various biochemical tests leads to delay in calculating the score and thus predicting the need for IRVS at the level of emergency room and hence we had to rely on faster methods such as curb-65 at the level of Emergency
Department to determine the site of care, although SMARTCOP assessment made the patient care plan formulation easy.

\section{REFERENCES}

1. Mandell LA, Wunderink RG, Anzueto A, et al. Infectious Diseases Society of America/American Thoracic Society Consensus Guidelines on the Management of Community-Acquired Pneumonia in Adults. Clin Inf Dis 2007;44:S27-72.

2. Lim WS, Baudouin SV, George RC, et al. BTS guidelines for the management of community acquired pneumonia in adults: update 2009. Thorax 2009;64(III):iii1-iii55.

3. Fine MJ, Auble TE, Yealy DM, et al. A prediction rule to identify low-risk patients with community-acquired pneumonia.

N Eng J of Med 1997;336:243-250.

4. Ewig S, Torres A, Woodhead M. Assessment of pneumonia Severity: A European perspective. Eur Respir J 2006;27:6-8.

5. Niederman MS. Making sense of scoring systems in community acquired pneumonia. Respirology 2009;14:327-335.

6. Charles PGP, Wolfe R, Whitby M, et al. SMART-COP: A tool for predicting the need for intensive respiratory or vasopressor support in community-acquired pneumonia. Clin Inf Dis 2008;47:375-384.

7. Angus DC, Marrie TJ, Obrosky DS, et al. Severe community-acquired pneumonia: use of intensive care services and evaluation of American and British Thoracic Society diagnostic criteria. Am J Respir Crit Care Med 2002;166:717-23.

8. Ewig S, de Roux A, Bauer T, et al. Validation of predictive rules and indices of severity for community acquired pneumonia. Thorax 2004;59:421-7.

9. SMART-COP: A Tool for Predicting the Need for Intensive Respiratory or Vasopressor Support in CommunityAcquired Pneumonia. Clin Infect Dis. (2008) 47 (3):375384 doi: $10.1086 / 589754$. 